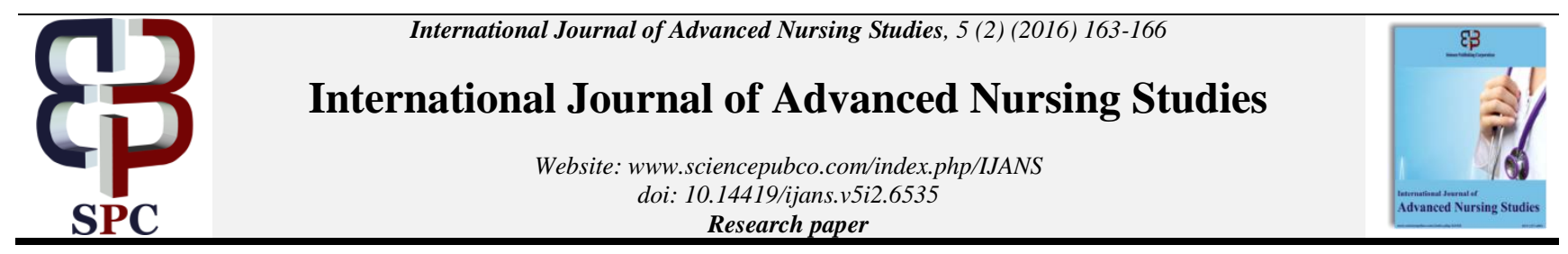

\title{
Hopes and dreams: poverty, motherhood and health care
}

\author{
Bonnie Pope $^{1 *}$, Kathaleen Bloom ${ }^{2}$ \\ ${ }^{1}$ Assistant Professor University of North Florida Brooks College of Health School of Nursing \\ ${ }^{2}$ Professor University of North Florida Brooks College of Health School of Nursing \\ *Corresponding author E-mail: b.pope@unf.edu
}

\begin{abstract}
Racial and ethnic differences in health outcomes exist in all areas of health care even when factors related to income; insurance status and access to care are controlled. The importance of the social environment versus biological influences a person's health status are explored in this study. Healthy People 2020 identified maternal health status to pregnancy-related health outcomes and African American women are at greater risk for poor pregnancy outcomes including increased rates of maternal, perinatal, neonatal, and infant mortality. Study Purpose: To understand the meaning of being and African-American woman living in poverty and their experiences with the health care system. Research Design: Exploratory qualitative, community-based participatory action research study used oral and digital storytelling. Participants and Setting: African American mothers residing in government subsidized housing.

Data Collection and Analysis: Focus groups, storytelling, and photovoice for data collection. Thematic analysis the focus groups' transcriptions and storyboard findings was conducted. Results: Common themes from the transcripts were "respect me...don't stereotype me" and "be safe." Themes from storyboards were "love of family," "love of community," and "hope for the future." Courage, family, and community are the foundation of their lives. Limitation: Sample size does not allow generalization to larger populations.
\end{abstract}

Keywords: Qualitative; Health Care; Race; Racism; African Americans; Focus Groups; and Photovoice.

\section{Introduction}

Racial and ethnic differences in the incidence, prevalence, mortality, morbidity or survival rates of disease, otherwise known as health disparities, exist in all areas of health care (National Institutes of Health [NIH] 2011). Although factors such as income, insurance status and access to care certainly contribute to the issue, disparities persist even when these factors are controlled for (Owen, Gldstein, Clayton, \& Segars 2013). The World Health Organization's Commission on Social Determinants of Health (2008) identified the importance of the social environment versus biological influences on a person's health status. These influences include education, housing, living wages, access to health care and healthy foods, justice, and freedom from racism, sexism, and discrimination (Satcher 2010).

\subsection{Problem statement}

Pregnancy-related health outcomes, intricately tied to maternal health status, are addressed in the health care agenda identified in Healthy People 2020 (United States Department of Health and Human Services, 2012). African American women are at greater risk for poor pregnancy outcomes including increased rates of maternal, perinatal, neonatal, and infant mortality (Owen et al. 2013). In 2010, the infant mortality rate in the United States was 6.14/1,000 overall; but 11.46/1,000 for African Americans (Matthews \& MacDorman 2013). Health indicators, such as poor birth outcomes, must be addressed in the context of the persons experiencing disparities (Lu \& Halfon 2003).

The lives of African American women living in poverty are influenced by stress, racism and distrust (Giscombé \& Lobel 2005; Schulz et al. 2006; Woods-Giscombé \& Lobel 2008). African
American women often experience inequitable treatment in health care facilities where their personhood is assaulted through the indifference of health care providers as well as widespread institutional disrespect (Israel, Farquhar, James, Schulz, \& Parker 2002). A continual climate of disrespect can negatively impact the health status of vulnerable populations (Schulz et al. 2006). One consideration when seeking solutions to these health disparities can be found by listening to the stories of African American women as they describe their experiences with and perceptions of the current health care system (Banks-Wallace 2002; Hall \& Powell 2011; Lee 2015).

\subsection{Aim of the study}

This study was conducted to understand the meaning of being and African-American woman living in poverty and their experiences with the health care system

\section{Conceptual model}

The nursing conceptual model Accessing Community Wisdom provides a lens through which to view nursing, communities, and health. In this conceptual model communities are recognized as vibrant encapsulations of individuals, issues, accomplishments, and needs. The values, meanings, ideals, and needs reflect the individuals who create them (Chinn 2004). The complexity of community settings provides nursing with opportunities to identify broader patterns of health. Yet, to understand communities requires nurses to authentically engage with communities. 


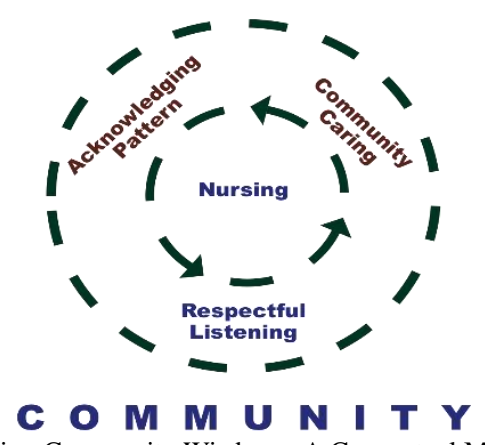

Fig. 1: Accessing Community Wisdom - A Conceptual Model (Developed by B. Pope).

There are three primary components of the model: respectful listening, acknowledging pattern, and community caring. Respectfu listening occurs as the nurse puts personal or professional agendas aside in order to hear what is being said and also to recognize what is not being said. This also includes "listening" to the community itself through observation. Communities, and the individuals within them, are the guardians of their own lived experiences, choosing what to reveal and how and to whom to reveal it. The information obtained from shared dialogue with community members and observations within the community allows discovery of themes and patterns. Acknowledging patterns occurs as the nurse and community members jointly identify personal, interpersonal, and environmental themes. A vibrant interrelatedness precludes isolation, prevents decay, and manifests itself in the physical patterns of the community (buildings, streets, businesses) and the activities of people and groups living within the community. Community caring is the authentic engagement with the diversity of a community. This involves honoring the wholeness of personhood of each community member and the relationship of the lived environment with all people well and sick.

Through respectfully listening to community members as they reveal their lived experiences, nurses witness emerging community patterns. Mutuality of meaning can guide the caring nurse to look for meanings in relationship with individuals, families, and communities and to honor diversity. It is the diversity in nature that gives the web of life its richness, strength and cohesion (Chinn 2004). The purpose of this study was to explore African American mothers' health care beliefs and experiences within the current health care system.

\section{Methods}

\subsection{Research design}

This was an exploratory qualitative, community-based participatory action research study using oral and digital storytelling. All study procedures were reviewed and approved by the Institutional Review Board at the University of North Florida.

\subsection{Participants and setting}

African American mothers residing in a government subsidized housing complex were recruited by first identifying a key informant in the community. Other women were identified using the snowball method wherein the key informant approached other mothers in the community explaining the purpose of the study using a script designed by the investigator. A total of five women initially agreed to participate and to attend a meeting with the investigator for a full explanation of the study and the opportunity to ask questions. At the conclusion of this meeting, participants were asked to sign a written informed consent. Two women decided not to participate, leaving three participants in the study. The first participant was an unmarried woman in her 50s. She had two grown children (a daughter and a son), two deceased children, and one grandchild. She had significant interactions with the health care system because of her diabetes and thyroid issues. The second participant was an unmarried woman in her 40s. She had one daughter and a pre-school age granddaughter. She did not reveal her health status. The third participant was an unmarried woman in her 30s. She had children, but did not reveal the number, gender and ages of children or her own health status.

\subsection{Data collection}

The study employed the use of focus groups, storytelling, and photovoice for data collection. Focus groups are used to bring together individuals around a common theme to explore perceptions and experiences through discussion and interaction (Powers 2015). A systematic review indicated that focus group research facilitates understanding of cultural norms and values and how they impact interactions with the health care system through listening to the collective perspectives of individuals within the group (Halcomb, Gholizadeh, DiGiacomo, Phillips \& Davidson 2007).

Storytelling, a way of sharing experiences and interpreting their meaning, is an integral component of the African-American oral tradition (Banks-Wallace 2001; Cherrington et al. 2015). This technique has been shown to be an effective means of understanding personal experiences and to present a different, more personal, perspective on such things as the aging process (Koch, Turnner, Smith, \& Hutnik 2010), adolescent sexual health (Gilliam et al. 2012), and combatting anti-vaccine misinformation (Shelby \& Ernst 2013).

Photovoice is a technique for gathering whereby participants are given cameras with which to take pictures around the theme of the research (Kowot et al. 2015). This community-based participatory research method has been widely used since its development over a decade ago. A systematic review of research utilizing photovoice indicates the potential for enhanced appreciation of the assets and needs of communities and the empowerment of individuals and groups within the community (Catalani \& Minkler 2010)

\subsection{Procedure}

The study took place over a three-week period of time.

\subsubsection{Week one}

A 90-minute focus group session was held in a private room at the neighborhood community center during which participants were asked to respond to five open-ended guiding questions (see Table 1). The entire session was audio-recorded. Participants were reminded of their right to withdraw from the study at any time and encouraged to not refer to each other by name.

At the end of the session, the investigator hosted a luncheon at a restaurant of the participants choosing, a local church-based soul food restaurant and ate in a private dining area. The group engaged in general conversation and was discouraged from discussing any information or experiences from the previous focus group. During the luncheon, each participant received a gift bag with a Vivitar digital camera, 4 batteries, and one memory card with instructions for its use (see Table 2). The participants were encouraged to open the cameras and insert memory cards and batteries. Test pictures were taken and shared with one another from the camera photo viewer. After all cameras were tested the instructions were reviewed and any questions from the participants were answered.

\subsubsection{Week two}

A second 90-minute audio-recorded focus group meeting was held in a private room at the community center. Participants were asked to discuss the experience of taking pictures and the meaning of the pictures as they created their personal storyboard. For this session there were no questions prepared to guide the discussion. The only instructions were to use the craft materials present to help them tell their story. During the group meeting time was given for any 
sharing of new insights into their perceptions on health care services and experiences. Art supplies (scissors, acrylic paints, construction paper, glue, glitter, and markers) were available as well as blank white 3' x 4' poster boards for the creation of the storyboards. The completed storyboards were stored in a locked metal cabinet at the neighborhood community center.

\subsubsection{Week three}

In the third and final 90-minute meeting, participants gathered in a private room at the neighborhood community center - this session was not audiotaped. The study's research assistant conducted an open discussion with one question - What does the board say about your perceptions on health care? Participants also discussed the group process. The group reflected on the various topics discussed during the two focus group sessions and reevaluated their experiences through their photos and the creation of individual storyboards representing their hopes and dreams. After the open discussion the P/I came into the meeting and studied the storyboards, considered potential themes present in each participant's storyboard. The P/I then presented the results from the previously completed thematic analysis of the two focus groups transcription and discussed those findings in relation to the storyboards.

\section{Results}

The audiotapes from all meetings were transcribed verbatim; audiotapes and transcriptions were kept confidential and maintained by the assignment of pseudo names. Data were kept in a secure, locked location and destroyed after study completion.

Data were analyzed using thematic analysis methodology to understand the identified themes in the context of the participants life experiences. Data from the transcripts and storyboards were reviewed for themes, clusters of themes, emerging patterns and the development of an overarching statement. The findings were shared with the participants during week three for verification and clarification.

\subsection{Focus groups}

The discussions during the focus groups centered primarily on the participants interaction within the health care system and on female health issues and staying healthy for themselves and for their daughters, granddaughters, and nieces. Common themes from the transcripts were "respect me...don't stereotype me" and "be safe".

\subsubsection{Respect me don't stereotype me}

The women reported receiving "good care" overall, but agreed that going to clinic appointments was "like being ignored or talked down to." Advice they would give nurses and other health care providers: "be kind and do your job" In describing an incident in the clinic, one woman said, "I have heard doctors ... they talk about people ...this lady had been pregnant for the $10^{\text {th }}$ time and they were in there just talking about her so bad. I thought everything was supposed to be confidential."

The women also described several perceived disparities in the care they received. One woman said, "What I don't like about it was the time that I was explaining it to the doctor, he tells me - he just stereotypes me." Another stated, "We black women, we go somewhere and they get the help before you." When asked to clarify, she responded "They don't give you proper right treatment like they do the white women. They be racist."

\subsubsection{Be safe}

These women identified several health issues as being important for black women, including hypertension, diabetes, and HIV. On a more general note, one woman said, "I also think we run ourselves in the ground so much to where we just ignore the facts about our health with black women." Advice they would give to other black women includes "talk to your mother and your doctor about female problems," "keep up with female hygiene," and "practice safe sex." And, finally, "sometimes people cry for help and we don't know what they're crying for so it's best for us to listen."

The women believed that more information for teenagers about preventing sexually transmitted diseases should be easily available and in a "real talk" format. As one participant stated, "we want to know - we want our children's lives to be happy and better." Another woman advises: "Your body is your body and nobody should touch it - it belongs to you; a woman's body is different than a man's. That's your gold mine." They advocated safe sex to protect against pregnancy "because you love that person that don't mean get pregnant. Ain't no need to get pregnant. It ain't going to hold them." They also urged vetting sexual partners in order to be as safe as possible "that's why these people getting these disease [HIV] because their partner not telling them who they're sleeping with."

\subsubsection{Storyboards}

The storyboards were a composite of pictures, painted images, glitter, fabric, and anything else that was available. These items created the visual expression of who the woman was at that point in time. Each participant shared her feelings about what the storyboard meant to her. Themes common to all storyboards were "love of family," "love of community," and "hope for the future". Even though there had been struggles and pain, lost children, lost mothers, and broken families the all the storyboards reflected hopefulness and joy, and the importance of family and community.

The participants' storyboards captured their ongoing struggles and joys. Comments written (such as "new day") revealed a search for happiness from nature and the fragrance from roses. Struggles over loosing children, mothers, grandmothers, and other family members were reflected in one simple thought. Shared with the group, "the trees are dying, you know the leaves on the tree are dying and they come back so I feel like I can too with a new life. And then that road with the sun again.,,, I'm not perfect and I'm not going to claim that, but I'm trying. I'm trying to get there; I guess is what I'm saying. It's real." Courage, family, and community are the foundation of their lives.

\subsubsection{Discussion}

The analysis of the focus group transcriptions yielded the overarching theme, "don't stereotype me." But what was even more interesting was the analysis of the photovoice storyboards; this overarching theme was "love of family, relationships, and community." The participants validated both overarching themes during the final meeting. This meeting was not part of the focus group schedule and therefore was not audio recorded and transcribed.

From the focus group transcriptions, participants were very concerned that nurses and doctors did not "give us respect and information to stay healthy." Another stated, "I want my daughter to be protected against [sexually transmitted] diseases." There was a dichotomy between their definition of themselves and the way that medical professionals defined them. Yet, from the storyboards there was a sense of hope and the future dreams for their families and themselves.

The women in the study demonstrated an ability to incorporate the strengths of family and social bonds and identified public and health policies designed to provide their families with education, health care, and economic opportunities in neighborhoods that often fail to support healthful lifestyles. The patterns that emerged highlighted the meanings the women attributed to their storyboards and in the intersection of the women's inner lives and their environmental influences. In their self-reflections, they sought the right words and pictures to tell their stories. The small sample size does not allow results to be generalized to larger groups. These results suggest that low-income women have an inner strength or resiliency, and when given the tools, can be their own agents of change. Future direction for similar qualitative studies could build 
upon this study by exploring the empowering aspects of their lived experiences.

\section{Limitations}

Limitations to the study include: sample size and inability to generalize finding to a larger population. Also it should be noted that documentation of findings could be further validated by audio recording all meetings and discussions.

Table 1: Guiding Questions for Focus Group Session

\section{Questions}

1) What advice would you give to your niece or daughter about going to the doctor for female problems?

2) Tell us about any home remedies you think work.

3) If you could talk to a group of doctors what would you tell them?

4) If you give nurses some advice what would it be?

5) If you could make a TV ad about women's health what would you say?

Table 2: Instructions for Digital Camera Use

1) Over the next week, take pictures of locations, buildings, gardens, parks, streets, etc. that will help you further explain what you were trying to say during the focus group.

2) Please do not include any pictures that may identify people. Pictures can be taken of crowds where there is no jeopardy of identifying someone. (An example would be blurred faces, the back of the head, etc.)

3) Please select 10 images that best explain your story of health care.

\section{References}

[1] Banks-Wallace J (2002). Talk that talk: Storytelling and analysis rooted in African American oral tradition. Qualitative Health Research, 12

410-426. http://dx.doi.org/10.1177/104973202129119892.

[2] Catalani C \& Minkler M. (2010). Photovoice: A review of the literature in health and public health. Health Education \& Behavior, 37, 424-451. http://dx.doi.org/10.1177/1090198109342084.

[3] Cherrington A, Williams JH, Foster PP, Coley HL, Kohler C, Allison, JJ, ... Houston TK (2015). Narratives to enhance smoking cessation interventions among African-American smokers, the ACCE project. Biomed Central Research Notes. 8, 567. http://dx.doi.org/10.1186/s13104-015-1513-1.

[4] Chinn P (2004). Peace and power: Creative leadership for building community (6th ed.). Boston, MA: Jones and Bartlett.

[5] Cohen MZ, Kahn D, \& Steeves RH, (2000). Hermeneutic phenomenological research: A practical guide for nurse investigators. Thousand Oaks, CA: California: Sage.

[6] Diekelmann NL \& Allen DG (1989). A hermeneutic analysis of the NLN criteria for the appraisal of baccalaureate programs. In $\mathrm{N}$. Diekelmann, D. Allen \& C. Tanner the NLN criteria for appraisal of baccalaureate programs: A critical hermeneutic analysis. New York: National League for Nursing.

[7] Gilliam M, Orzalli S, Heathcock S, Sutherland E, Jagoda P, Menendez A, Ojengbede O (2012). From intervention to invitation: reshaping adolescent sexual health through story telling and games. African Journal of Reproductive Health, 16, 189-196. Retrieved from http://www.ajrh.info/home/index.php.

[8] Giscombé CL \& Lobel M (2005). Explaining disproportionately high rates of adverse birth outcomes among African Americans: The impact of stress, racism, and related factors in pregnancy. Psychological Bulletin, 131, 662-683. http://dx.doi.org/10.1037/00332909.131.5.662.

[9] Halcomb EJ, Gholizadeh L, DiGiacomo M, Phillips J, \& Davidson PM (2007). Literature review: Considerations in undertaking focus group research with culturally and linguistically diverse groups. Journal of Clinical Nursing, 16, 1000-1011. http://dx.doi.org/10.1111/j.1365-2702.2006.01760.x.

[10] Hall JM \& Powell J (2011). Understanding the person through narrative. Nursing Research and Practice, 2011(Art. No. 293837) http://dx.doi.org/10.1155/2011/293837.

[11] Healthy People 2020 (2012, June 20). HealthyPeople.gov. Retrieved from http://www.healthypeople.gov/2020/default.aspx.

[12] Israel BA, Farquhar S, James SA, Schulz AM, \& Parker EA (2002) The relationship between social support, stress and health among women on Detroit's east side. Health Education \& Behavior, 29, 342-360. http://dx.doi.org/10.1177/109019810202900306.

[13] Koch T, Turner R, Smith P, \& Hutnik N (2010). Storytelling reveals the active, positive lives of centenarians. Nursing Older People, $22(8)$

31-36. http://dx.doi.org/10.7748/nop2010.10.22.8.31.c7995.

[14] Kowitt S, Woods-Jaeger B, Lomas J, Taggart T, Thayer L, Sutton S Lightfoot AF (2015). Using photovoice to understand barriers to and facilitators of cardiovascular health among African American adults and adolescents, North Carolina, 2011-2012. Preventing
Chronic
Disease,
12,150062 http://dx.doi.org/10.5888/pcd12.150062.

[15] Lee B (2015). Storytelling to enhance the value of research. American Journal of Public Health, 105(4). http://dx.doi.org/10.2105/AJPH.2014.302548.

[16] Lu MC \& Halfon N (2003). Racial and ethnic disparities in birth outcomes: A life-course perspective. Maternal and Child Health Journal, 17, 13-30. Retrieved from http://link.springer.com/journal/10995. http://dx.doi.org/10.1023/A:1022537516969.

[17] Matthews MS \& MacDorman MF (2013). Infant mortality statistics from the 2010 period linked birth/infant death data set. National Vital Statistics Reports, 62(8). Hyattsville, MD: National Center for Health Statistics. Retrieved from http://www.cdc.gov/nchs

[18] Powers BA (2015). Critically appraising qualitative evidence for clinical decision making. In Melnyk B \& E Fineout-Overholt (eds.), Evidence-based practice in nursing and health care: A guide to best practice (3rd ed., pp. 139-168). Philadelphia, PA: Wolters Klewer Health.

[19] National Institutes of Health (2011). NIH policy on reporting race and ethnicity data: Subjects in clinical research. Bethesda, MD: Author. Retrieved from http://grants.nih.govlgrants/guidelnoticefilesLNOT-OD-01-053.html

[20] Owen CM, Goldstein, EH Clayton, JA \& Segars, JH (2013). Racial and ethnic health disparities in reproductive medicine: An evidence-based overview. Seminars in Reproductive Medicine, 31, 317-324. http://dx.doi.org/10.1055/s-0033-1348889.

[21] Satcher D (2010). Include a social determinants of health approach to reduce health disparities. Public Health Reports, 125(Suppl. 4) 67. Retrieved from http://www.publichealthreports.org/

[22] Schulz AJ, Israel BA, Zenk SN, Parker EA, Lichtenstein R, Shellman-Weir S, \& Klem AB (2006). Psychosocial stress and social support as mediators of relationships between income, length of residence and depressive symptoms among African American women on Detroit's eastside. Social Science \& Medicine, 62, 510522. http://dx.doi.org/10.1016/j.socscimed.2005.06.028.

[23] Shelby A, \& Ernst K (2013). Story and science: How providers and parents can utilize storytelling to combat anti-vaccine misinformation. Human Vaccines \& Immunotherapies, 9, 1795-1801. http://dx.doi.org/10.4161/hv.24828.

[24] [24] United States Department of Health and Human Services (2012). Healthy People 2020. Retrieved from www.healthypeople.gov

[25] Woods-Giscombé CL \& Lobel M (2005). Race and gender matter: A multidimensional approach to conceptualizing and measuring stress in African American women. Cultural Diversity \& Ethnic Minority Psychology, 14, 173-182. http://dx.doi.org/10.1037/10999809.14.3.173.

[26] World Health Organization (2008). Closing the gap in a generation: Health equity through action on the social determinants of health. Report from the Commission on Social Determinants of Health. Geneva, Switzerland: Author. Retrieved from http://www.who.int/social_determinants/thecommission/finalreport/ en/index.html. 